\title{
INHIBITION OF OVULATION BY INTRACRANIAL IMPLANTATION OF PROGESTERONE IN THE 4-DAY CYLIC RAT
}

\author{
A. P. LABHSETWAR* AND J. G. BAINBRIDGE \\ Imperial Chemical Industries Limited, Pharmaceuticals Division, Alderley Park, \\ Macclesfield, Cheshire
}

(Received 11th March 1971, revised 19th Fuly 1971)

\begin{abstract}
Summary. Crystalline progesterone or cholesterol $(50 \mu \mathrm{g} / \mathrm{rat})$ was implanted stereotaxically into the anterior pituitary gland or median eminence region on the day before pro-oestrus in the 4-day cyclic rat, and the effects of these steroids on ovulation were studied by examining tubal ova at autopsy on the expected day of oestrus. Progesterone (at $1 / 10$ the effective subcutaneous dose) implanted at either location proved significantly more active in interfering with ovulation than cholesterol $(P<0 \cdot 01)$. The data provide evidence that progesterone acts at both the hypothalamic and pituitary levels to interfere with ovulation.
\end{abstract}

Earlier studies have demonstrated that progesterone acts at both ovarian (Redmond, 1968; Stevens, Spies, Hilliard \& Sawyer, 1970; Labhsetwar, 1971) and pituitary (Stevens et al., 1970; Labhsetwar, 1971) levels to interfere with ovulation, but whether or not its targets include the central nervous system has not been unequivocally demonstrated. A relatively large implant $(400 \mu \mathrm{g})$ of progesterone placed in the hypothalamus delayed puberty and the formation of corpora lutea, but a similar implant in the anterior pituitary proved ineffective (Smith, Weick \& Davidson, 1969). Because the evidence for the involvement of the central nervous system is circumstantial and often contradictory, we have stereotaxically implanted progesterone into the median eminence region or anterior pituitary gland and studied its effects on ovulation by examining tubal ova at autopsy on the day of expected oestrus.

Adult, sexually mature rats of Alderley Park strain I, which were Wistarderived and bred randomly for several generations under pathogen-free conditions, were used. They were housed under controlled conditions of light (from 06.00 to 20.00 hours) and temperature $\left(22^{\circ} \mathrm{C}\right.$ ), and allowed free access to a standard diet and tap water. Rats were selected for a close body weight range ( 160 to $180 \mathrm{~g}$ ) and regular oestrous cycles of 4 days. Each rat used had at least two consecutive 4-day oestrous cycles before use. They were anaesthetized with pentobarbitone $(30 \mathrm{mg} / \mathrm{kg}$, i.p.) supplemented with halothane on the

* Present address: Worcester Foundation for Experimental Biology, Shrewsbury, Mass. 01545, U.S.A. 
morning of the day before pro-oestrus. This dose of barbiturate has been found to be virtually ineffective in interfering with ovulation when given at this time in the cycle (Labhsetwar, unpublished observations; Brown-Grant, 1969). The rats were then placed in a stereotaxic instrument and a needle bearing a mixture of cocoa butter and progesterone was lowered to a desired location, i.e. the median eminence region or anterior pituitary gland, by the technique described by Bainbridge \& Labhsetwar (1971). The presence of a hole in the median eminence region or on the dorsal surface of the pituitary gland at autopsy confirmed the original positioning of the tip of the needle. The 'pellet', estimated to contain $1.7 \mathrm{mg}$ cocoa butter mixed with $50 \mu \mathrm{g}$ steroid, was ejected and the needle was then withdrawn. Control implants consisted of cocoa butter mixed with $50 \mu \mathrm{g}$ cholesterol. The cholesterol was obtained commercially and recrystallized before use to remove impurities.

TABLE 1

EFFECTS OF GRADED DOSES OF PROGESTERONE ADMINISTERED SUBCUTANEOUSLY AT 17.00 HOURS ON THE DAY OF DIOESTRUS ON OVULATION IN THE 4-DAY CYGLIG RAT

\begin{tabular}{|c|c|c|c|c|c|c|}
\hline $\begin{array}{c}\text { Dose } \\
\text { (mgl } \\
\text { animal }\end{array}$ & $\begin{array}{c}\text { Body } w t \dagger \\
(g)\end{array}$ & $\begin{array}{c}\text { No. rats } \\
\text { ovulating/ } \\
\text { No. } \\
\text { treated }\end{array}$ & $\begin{array}{c}\text { Ova/ } \\
\text { ovulating } \\
\text { rat } \dagger\end{array}$ & $\begin{array}{c}\text { Ovarian } \\
w t(m g) \dagger\end{array}$ & $\begin{array}{l}\text { Uterine } \\
w t(m g) \dagger\end{array}$ & $\begin{array}{l}\text { No. of rats } \\
\text { with cornified } \\
\text { smears } \\
\text { Total no. }\end{array}$ \\
\hline $\begin{array}{l}0 \\
0 \cdot 25 \\
0 \cdot 5 \\
1 \cdot 0 \\
2 \cdot 0 \\
4 \cdot 0\end{array}$ & $\begin{array}{l}216 \pm 6 \\
207 \pm 6 \\
200 \pm 6 \\
193 \pm 7 * \\
202 \pm 4 \\
214 \pm 4\end{array}$ & $\begin{array}{l}5 / 5 \\
4 / 5 \\
0 / 10 \\
0 / 5 \\
0 / 4 \\
0 / 9\end{array}$ & $\begin{array}{c}12 \cdot 2 \pm 0 \cdot 7 \\
10 \cdot 0 \pm 0 \cdot 7 \\
0 \\
0 \\
0 \\
0\end{array}$ & $\begin{array}{l}94 \pm 5 \\
94 \pm 7 \\
82 \pm 4 \\
76 \pm 4^{*} \\
75 \pm 5^{*} \\
66 \pm 8^{*}\end{array}$ & $\begin{array}{l}371 \pm 33 \\
346 \pm 5 \\
345 \pm 22 \\
326 \pm 28 \\
289 \pm 11 \\
240 \pm 14^{*}\end{array}$ & $\begin{array}{l}5 / 5 \\
5 / 5 \\
5 / 5 \\
8 / 10 \\
0 / 4 \\
0 / 9\end{array}$ \\
\hline
\end{tabular}

$* P<0.05$.

$\dagger$ Values expressed as Means \pm S.E.

Vaginal smears were taken daily until autopsy on the morning of the expected day of oestrus, i.e. approximately $48 \mathrm{hr}$ after surgery. To study the extent of diffusion of steroid and cocoa butter, the experiment was repeated using two rats/group with the difference that the steroid in the pellet was replaced with Sudan Black. After autopsy, the brains of these rats were serially sectioned, and photographed. Diffusion of dye could be easily studied in the photographs. From implants placed into the median eminence region, dye had diffused into the third ventricle and had also migrated along the path of the needle. No diffusion to the hypophysial region could be seen in either rat. When implants were placed into the anterior pituitary, the dye diffused into the space between the hypophysis and the ventral surface of the hypothalamus. It had also penetrated the brain along the needle path in the mammillary region. Thus, while our study permits differentiation of effects of implants between the hypothalamus and anterior pituitary, it does not permit further resolution with respect to specific hypothalamic nuclear groups. At autopsy, uterine and ovarian weights were recorded and the number of tubal ova/rat determined. In a few groups of rats, progesterone was administered subcutaneously to determine the minimal effective dose by the systemic route. All data were 


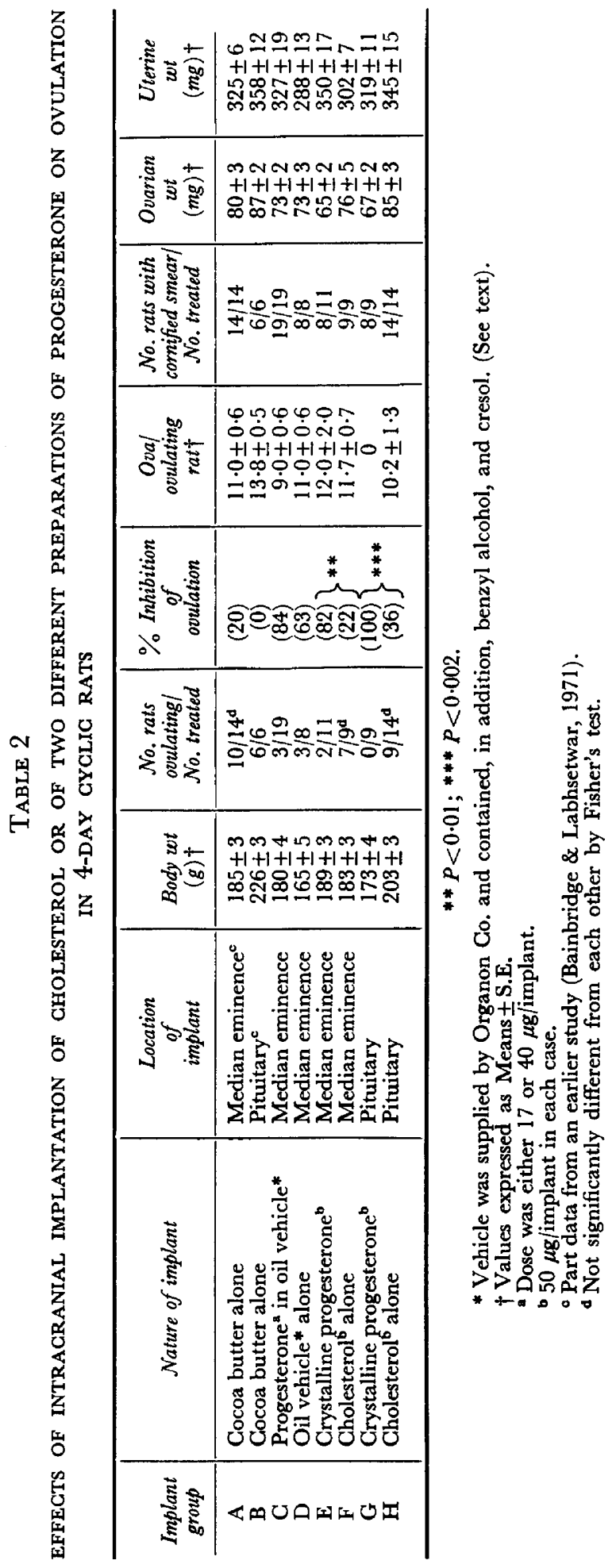


analysed for statistical significance by a computerized $t$ test or by Fisher's exact probability test using Finney's tables (Siegel, 1956).

In rats given progesterone subcutaneously in oil late in dioestrus, i.e. at 17.00 hours, and killed on the morning of expected oestrus, the minimum dose effective in blocking ovulation was found to be $0.5 \mathrm{mg}$ (Table 1). At this dose, inhibition of ovulation was not accompanied by any interference with vaginal cornification or uterine weight increase (Table 1). However, both of these responses were blocked or modified by doses of progesterone in excess of $2 \mathrm{mg}$ and ovarian weights were reduced.

A tenth of the smallest systemically active dose of progesterone was selected for intracranial implantation. In the initial experiment, progesterone dissolved in oil and other organic solvents as supplied by Organon Laboratories Ltd was used and proved highly effective in interfering with ovulation when implanted into the median eminence region (Group G). However, similar effects were exerted by the vehicle alone (Group D). According to the supplier, the vehicle was composed of arachis oil mixed with $10 \%$ benzyl alcohol and $0.3 \%$ cresol. It is apparent from these results that non-specific substances can also interfere with ovulation.

The entire experiment was then repeated with crystalline progesterone (B.D.H., Poole) and recrystallized cholesterol made up in cocoa butter which was known to be only marginally effective by itself in interfering with ovulation (Table 2, Group A). A dose of $50 \mu \mathrm{g}$ progesterone implanted either into the median eminence region or anterior pituitary gland proved significantly more active than a similar dose of cholesterol in inhibiting ovulation $(P<0.01$ in each case, Groups $\mathrm{E}$ to $\mathrm{H}$ ) and no interference with vaginal cornification or uterine weight increase was observed (Table 2). This selective action of progesterone suggests that its effect was not exerted at the peripheral level. Our data thus suggest that intracranially implanted progesterone can act both at the hypothalamic and pituitary level to inhibit ovulation. This, however, does not mean that during pregnancy or pseudopregnancy endogenously produced progesterone acts selectively at those sites. If it is assumed that the daily output in rats exceeds $2.0 \mathrm{mg} /$ day, it may well act, in addition, directly on the ovaries, as demonstrated earlier (Stevens et al., 1970; Labhsetwar, 1971).

The authors gratefully acknowledge the skilled technical assistance of Miss Rosemary Chester and Miss J. Turner, and wish to thank Organon Laboratories Ltd for supplying the progesterone vehicle.

\section{REFERENCES}

Baingridge, J. G. \& Labhset war, A. P. (1971) The role of oestrogens in spontaneous ovulation: location of site of action of positive feedback of oestrogen by intracranial implantation of antioestrogen-ICI 46,474. F. Endocr. 50, 321.

Brown-Grant, K. (1969) Effects of progesterone and of pentobarbitone administered at the dioestrous stage on the ovarian cycle of the rat. F. Endocr. 43, 539.

LABHSETWAR, A. P. (1971) Exploration of site(s) of action of progesterone in inhibiting ovulation in rats. Biol. Reprod. (In press). 
REDMond, W. C. (1968) Ovulatory response to brain stimulation or exogenous luteinizing hormone in progesterone-treated rats. Endocrinalogy, 83, 1013.

SiEgel, S. (1956) Nonparametric statistics for the behavioural sciences. McGraw-Hill, New York.

Smith, E. R., Weick, R. F. \& Davidson, J. M. (1969) Influence of intracerebral progesterone on the reproductive system of female rats. Endocrinology, 85, 1129.

Stevens, K., Spies, H., Hilliard, J. \& Sawyer, G. H. (1970) Site(s) of action of progesterone in blocking ovulation in the rat. Endocrinology, 86, 970. 